\title{
Interactive comment on "The new importance measures based on vector projection for multivariate output: application on hydrological model" by L. Xu et al.
}

\section{Solomatine (Editor)}

d.solomatine@unesco-ihe.org

Received and published: 20 December 2016

\section{Dear authors,}

Indeed an interesting publication presenting a method for multi-objective sensitivity analysis. It may be a useful contribution to the arsenal of methods used by hydrological modellers.

However reviewers rightfully indicate that the way the method is presented and tested is not what the readers of this journal would typically expect. The hydrological problem to be solved is not covered well, and it is more a presenteation of a universal method; if so, this paper in this form has to be published elsewhere. 
However, given the authors want to address all the referees' comments, and to a large extent to rewrite the paper for the HESS audience, I am inviting them to do it. Referees provide very good comments and suggestions how to change and improve the paper. Please address all comments one by one, and indicate what is changed in the manuscript. I would advise to check other papers on uncertainty analysis of hydrological models, including those published in HESS - to understand what are the main compoenents and logical structure of a typical paper on this subject.

I would like to stress that you have to do much more on improving English. After all this is done, the paper will be sent for a review again.

In a separate email I will also be sending a document "Preparing a paper and dealing with reviews" which may help during ther revision process.

Interactive comment on Hydrol. Earth Syst. Sci. Discuss., doi:10.5194/hess-2016-259, 2016. 